\title{
Pharmacokinetic Study of Modafinil in Relation to Gender and Ethnicity in Healthy Young Chinese Volunteers
}

\author{
Tao Guo ${ }^{1}$, Long-shan Zhao ${ }^{1,2}$, Dong-Ya Xia ${ }^{1}$ \\ ${ }^{1}$ Department of Pharmacy, Shenyang Northern Hospital, Shenyang 110016, China \\ ${ }^{2}$ Department of Pharmacy, Shenyang Pharmaceutical University, Shenyang 110016, China
}

Received, May 23, 2010; Revised, October 28, 2010; Accepted, October 29, 2010; October 29, 2010.

\begin{abstract}
Purpose. Pharmacokinetics of modafinil were investigated in relation to sex and ethnicity in healthy young volunteers from Han, Mongolian, Korean, Uygur and Hui $(n=10$ group) following administration of a single $200 \mathrm{mg}$ oral dose. Methods. Blood samples were collected over $48 \mathrm{~h}$ for the determination of plasma levels of modafinil and its acid metabolite by HPLC. Pharmacokinetic parameters were evaluated using noncompartmental methods. Results. Modafinil was well tolerated and safe at a single oral dose of $200 \mathrm{mg}$. All participants reported adverse events, none of which was serious or unexpected. The maximum plasma concentration $\left(C_{\max }\right)$ and area under the curve for modafinil concentration versus time, which was extrapolated to infinity $\left(\mathrm{AUC}_{0-\infty}\right)$, were higher in women compared to men $(p<0.01)$. No sex-based difference was noted in the total body weight-normalized modafinil oral clearance. The total body weight-normalized modafinil apparent volume of distribution and $t_{1 / 2}$ were found to exhibit ethnicity-based significant differences. Conclusion. There are pharmacokinetic differences based on sex and ethnicity for modafinil.
\end{abstract}

\section{INTRODUCTION}

Modafinil ( $\pm-2-[($ diphenylmethyl) sulfinyl] acetamide, Figure 1), as a novel wake-promoting psychostimulant discovered by Laboratoier L. Lafon (Maisons Alfort, France), was initially investigated for the treatment of excessive daytime sleepiness (EDS) associated with narcolepsy (1). Recent evidence has indicated that modafinil is effective in the treatment of excessive day-time sleepiness (and fatigue) in disorders other than narcolepsy, such as idiopathic hypersomnia (2), night-shift sleep disorder (3), obstructive sleep apnoea (4), multiple sclerosis (5), Parkinson's disease (6), myotonic dystrophy (7), depression (8), schizophrenia (9), attention-deficit disorder (10), and cocaine dependence and withdrawal (11). The exact mechanism of its wake-promoting activity in the brain is still under investigation, however, it has been reported that it may indirectly increase wakefulness partly through inhibition of gama aminobutyric acid (GABA) release via serotonergic mechanisms (12). Modafinil has a low abuse potential (13), which produces relatively small changes in cardiovascular activity at clinical doses (14), and does not demonstrate signs of tolerance to its wake-promoting effects even after 12 months of treatment (15). Modafinil is metabolized into two major metabolites, modafinil acid (2-[(diphenylmethyl) sulfinilyl] acetic acid) and modafinil sulfone (2-[(diphenylmethyl) sulfanilyl] acetamide; Figure 1), which are inactive and the acid metabolite accounts for more than $60 \%$ of the dose (16). The sulfone metabolite is found in minute quantities in plasma so we haven't investigated it in this present study.

Modafinil is well absorbed following oral administration with a terminal half-life of 10 to 15 $\mathrm{h}$, which exhibits linear pharmacokinetics following oral doses ranging from 50 to $400 \mathrm{mg}$. The oral clearance $(\mathrm{CL} / \mathrm{F})$ of modafinil is 50 to $60 \mathrm{~mL} / \mathrm{min}$, and the apparent volume of distribution $(\mathrm{Vd} / \mathrm{F})$ is 50 to $60 \mathrm{~L}$ which indicates the possibility of tissue binding. Its plasma protein binding reaches approximately $60 \%$ (17). In addition, the $\mathrm{CL} / \mathrm{F}$ of modafinil in females is reported to be approximately $22 \%$ higher than that in males (16).

Pharmacokinetic differences between sexes and ethnic groups have been reported (18-20). Furthermore, sex-specific differences such as menopause, menstruation and the use of contraceptives may influence pharmacokinetics and pharmacodynamics (21). Thus, it is important to investigate possible ethnicity- and sex-based differences in modafinil pharmacokinetics in healthy young Chinese volunteers.

The purpose of the present study was to examine the influence of ethnicity and sex on the pharmacokinetics of modafinil following of a single

Corresponding Author: Tao Guo; Department of Pharmacy, Shenyang Northen Hospital, Shenyang 110016; China; Email: sy_guotao@263.net 
$200 \mathrm{mg}$ oral doses of modafinil in Chinese Han, Mongolian, Korean, Uygur and Hui healthy subjects in China. To the best of our knowledge this is the first evaluation of the influence of sex and ethnicity on modafinil pharmacokinetic profile after a single oral dose of modafinil tablets in healthy Chinese volunteers.

\section{METHODS}

\section{Study Population}

Fifty healthy young male and female volunteers were recruited from Shenyang in Liaoning, Chifeng in Inner Mongolia, Yanji in Jilin, Urumqi in Xinjiang, and Yinchuan in Ningxia, thus comprising the five ethnic groups $(n=10$ /group). Whose parents, grandparents and adoptive grand-parents all had married within the same ethnicity. All participants were students of the local Medical or Pharmaceutical University who were informed of the objectives, procedures, and risks involved in the study prior to participation. All participants were judged to be healthy according to a pre-study physical examination, which included a medical history and routine biochemical blood analyses. All of the participants' examination data were in the normal range. All medications were forbidden for at least two weeks prior to study participation and alcohol or cigarettes were forbidden for at least $72 \mathrm{~h}$ prior to drug administration and for the duration of the testing period. All 25 females were tested during the luteal phase of their menstrual cycle. The study protocol followed the Declaration of Helsinki and was approved by the independent Ethical Committee of the Shenyang Northern Hospital. All participants provided written informed consent prior to enrollment.

\section{Study Design and Procedures}

The current study was designed as a single-dose, parallel-group protocol performed in young healthy male and female adults across five different ethnicities in China. Each study phase began at 7:00 a.m. (Beijing Time). All subjects were given uniform diets to follow prior to testing and then fasted overnight prior to modafinil dosing. A single oral dose of a $200 \mathrm{mg}$ modafinil tablets was given with $200 \mathrm{~mL}$ of water to each subject. Subjects continued fasting for $2 \mathrm{~h}$ following administration. During the test period, all participants remained under close medical supervision and continued the uniform diet.

\section{Blood Sample Collection}

Blood samples $(4 \mathrm{~mL})$ were collected into heparinized tubes prior to modafinil administration and at $0.25,0.5,1,1.5,2,3,4,6,8,12,24,36$, and $48 \mathrm{~h}$ following oral dosage. Samples were immediately centrifuged at $3500 \mathrm{r} / \mathrm{min}$ for $8 \mathrm{~min}$, and the plasma was separated and frozen at $-25^{\circ}$ until analyzed.

\section{Analysis of Plasma Samples}

Plasma concentrations of modafinil and modafinil acid were evaluated using HPLC (22). Plasma (0.2 $\mathrm{mL}$ ) was mixed with $100 \mu \mathrm{L}$ of internal standard solution, and $0.5 \mathrm{~mL}$ of methanol. The mixture was vortex-mixed for $1 \mathrm{~min}$ and centrifuged at 15000 $\mathrm{r} / \mathrm{min}$ for $8 \mathrm{~min}$. Then $20 \mu \mathrm{L}$ of the supernatant was injected onto a $4.6 \mathrm{~mm}$ internal diameter $\times 200 \mathrm{~mm}$ Diamonsil $\mathrm{C}_{18}$ column with ultraviolet detection at $220 \mathrm{~nm}$. The calibration curve showed good linearity over the range of $0.1-10 \mu \mathrm{g} / \mathrm{mL}$ for modafinil and modafinil acid with intra-day and inter-day relative standard deviations (RSD) of less than $11 \%$ at all levels. The relative recoveries of modafinil were $(86.9 \pm 3.5) \%$, $(86.9 \pm 4.2) \%$, and $(96.8 \pm 1.8) \%$ and of modafinil acid were $(98.8 \pm$ $1.6) \%,(92.8 \pm 6.3) \%$, and $(88.3 \pm 5.3) \%$ at $0.2,1.0$, and $8.0 \mu \mathrm{g} / \mathrm{mL}$ of quality control (QC), respectively.

\section{Statistical Analysis}

Statistical analyses were performed by using SPSS software (version 11.5; SPSS Inc., Chicago, IL, USA). For $\mathrm{C}_{\max }, \quad \mathrm{AUC}_{0-\mathrm{t}}, \quad \mathrm{AUC}_{0-\infty}$, natural $\log$-transformation of the data was used. Values for $T_{\max }$ were compared using nonparametric Wilcoxon two-sample test. Analysis of variance (ANOVA) was used to determine the difference in pharmacokinetic data among ethnicity levels. Comparisons of the pharmacokinetic parameters between different sex levels were evaluated by paired t-test. Descriptive statistics were expressed as mean \pm standard deviation (SD) values. All tests of hypotheses were two-sided, and a $P$ value $<0.05$ or $<0.01$ was considered statistically significant (23).

\section{RESULTS}

\section{Subjects}

A total of 50 healthy volunteers participated in this study. One Korean subject withdrew from the study after the drug administration at his own request. The remaining 24 male participants had a mean age of 23 years (range: 19-26), a mean height of $173 \mathrm{~cm}$ (range: 162-184), and a mean weight of $66 \mathrm{~kg}$ (range: 56-88). The 25 young healthy female participants had a mean age of 22 years (range: 18-24), a mean height of $161 \mathrm{~cm}$ (range: 150-167), and a mean weight of $56 \mathrm{~kg}$ (range: 44-80). The mean $\pm \mathrm{SD}$ values are listed in Table 1 . 


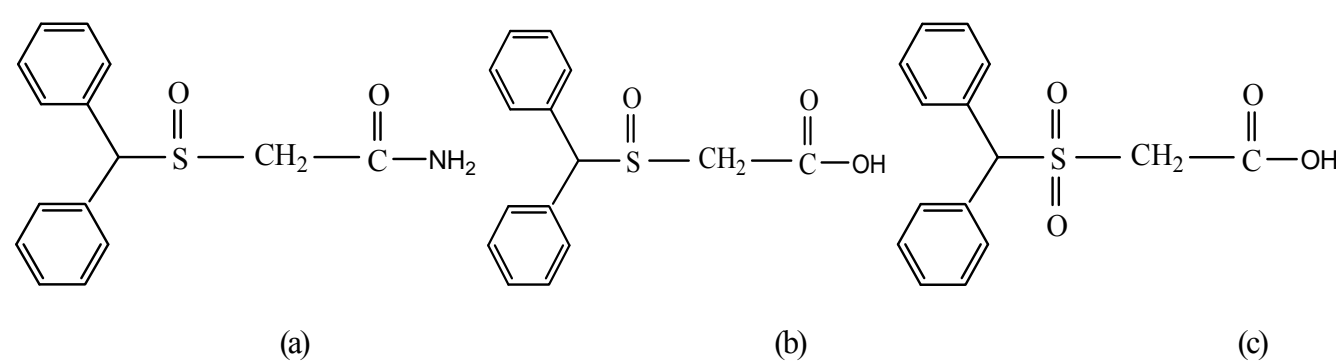

Figure 1. Chemical structures of modafinil (a), modafinil acid (b), and modafinil sulfone (c)

\begin{tabular}{|c|c|c|c|c|c|}
\hline Ethnicity & Sex & $\mathrm{n}$ & Age (y) & Height $(\mathrm{cm})$ & Weight $(\mathrm{kg})$ \\
\hline \multirow{2}{*}{ Han } & $\mathrm{M}$ & & $24.8 \pm 0.8$ & $170.4 \pm 5.90$ & $64.2 \pm 6.1$ \\
\hline & $\mathrm{F}$ & & $23.6 \pm 0.9$ & $161.2 \pm 3.83$ & $53.8 \pm 3.6$ \\
\hline \multirow{2}{*}{ Mongolia } & M & & $23.8 \pm 0.8$ & $174.8 \pm 2.59$ & $62.4 \pm 3.4$ \\
\hline & $\mathrm{F}$ & & $21.8 \pm 0.5$ & $160.0 \pm 6.82$ & $69.6 \pm 15.4$ \\
\hline \multirow{2}{*}{ Korea } & M & & $23.0 \pm 1.2$ & $178.5 \pm 5.97$ & $70.5 \pm 8.8$ \\
\hline & $\mathrm{F}$ & & $22.2 \pm 0.8$ & $156.0 \pm 5.29$ & $48.2 \pm 4.4$ \\
\hline \multirow{2}{*}{ Uygur } & M & & $22.4 \pm 0.6$ & $170.4 \pm 2.70$ & $66.2 \pm 5.8$ \\
\hline & $\mathrm{F}$ & & $20.4 \pm 1.5$ & $161.8 \pm 3.19$ & $52.8 \pm 2.8$ \\
\hline \multirow{2}{*}{ Hui } & M & & $21.4 \pm 1.8$ & $172.0 \pm 8.49$ & $69.8 \pm 11.8$ \\
\hline & $\mathrm{F}$ & & $20.8 \pm 1.1$ & $163.6 \pm 3.71$ & $53.6 \pm 7.6$ \\
\hline
\end{tabular}

\section{Safety}

No serious adverse events occurred during the study. The one participant withdrew of his own will, and thus, this was not recorded as an adverse event. Nonserious adverse events included the following: One Mongolian participant suffered a headache and fever following administration, but recovered within a day from the symptoms. The most commonly reported adverse events were headache (11/49), nausea (6/49), fever (3/49) and asthenia $(22 / 49)$. All of the treatment-emergent adverse events were recorded as mild in severity, there was no subjects discontinued from the study due to adverse events. No clinically important changes in respiratory rate, in body temperature, or in physical examination parameters were observed.

\section{Pharmacokinetics}

The mean plasma concentration $\pm \mathrm{SD}$ versus time profiles of modafinil and modafinil acid are shown in Figure 2, 3, 4 and the pharmacokinetic parameters are listed in Tables 2 and 3.

Figure 2 illustrates the mean plasma concentration-time profiles of modafinil and modafinil acid obtained for 49 subjects after administration of a $200 \mathrm{mg}$ oral dose. Both of them were absorbed rapidly reaching at the maximum concentration of $1.83 \pm 0.71 \mathrm{~h}$ for modafinil and $2.80 \pm 1.06 \mathrm{~h}$ after administration. Figure 3 illustrates that the values of $\mathrm{C}_{\max }, \mathrm{AUC}_{0-\mathrm{t}}$ and $\mathrm{AUC}_{0-\infty}$ for females are obviously larger than that of males for both modafinil and modafinil acid. While the Figure 4 illustrates that except the profile of Korean, the remaining profiles are similar to each other. The profile is not well superimposible, indicating that there might be some sex- or ethnicity-based differences in the pharmacokinetic patterns of modafinil.

Using standard noncompartmental methods to calculate the pharmacokinetic parameters would avoid the different results from the influence of compartment model and its weight, and be better to compare the results with that reported. The results of pharmacokinetic parameters are consistent with those reported by others (24-26) and could be served as the basic of the evaluation for the influence of ethnicity and sex.

Previous clinical studies have indicated that a single oral dose of $200 \mathrm{mg}$ modafinil tablets is therapeutically effective, safe and tolerated (17). There was no unexpected or serious adverse events when modafinil was given to the five study groups. 


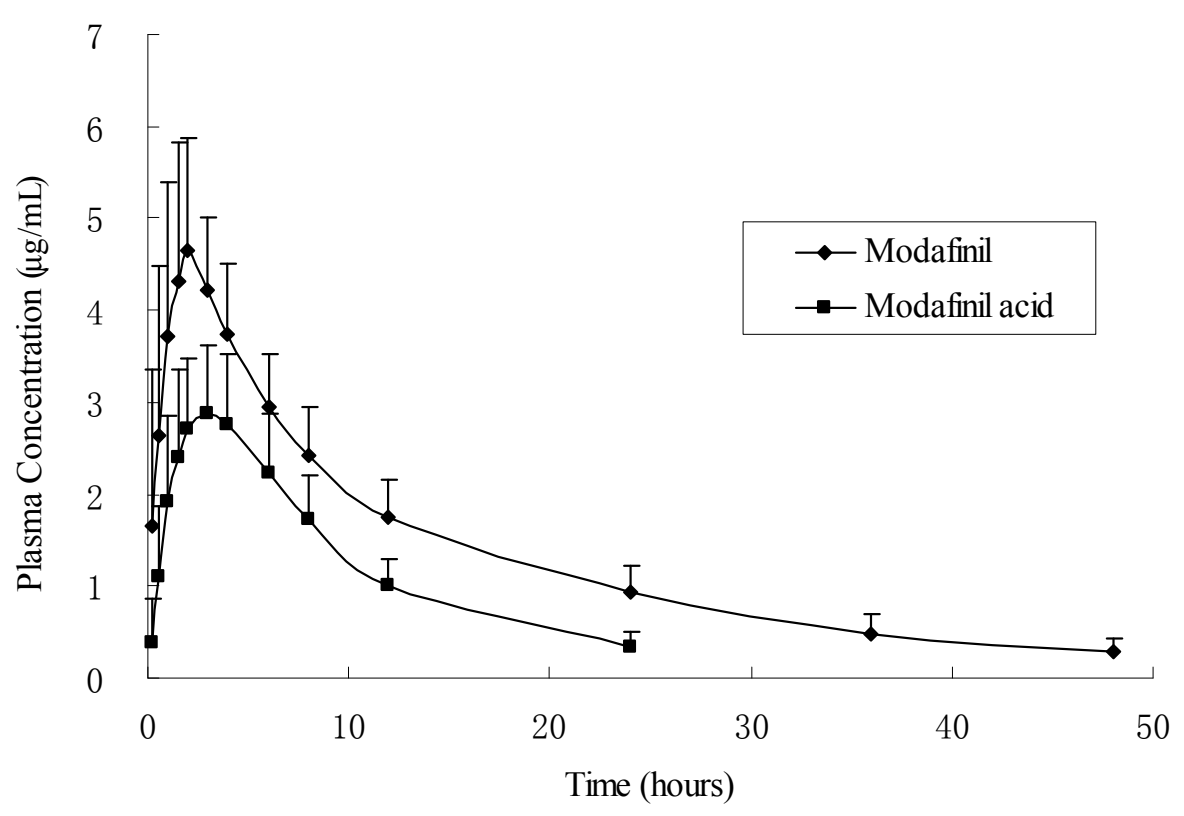

Figure 2. Plasma concentration - time profiles of modafinil and modafinil acid following a single oral administration of a $200 \mathrm{mg}$ modafinil tablets. Each point represents mean $\pm S D(n=49)$

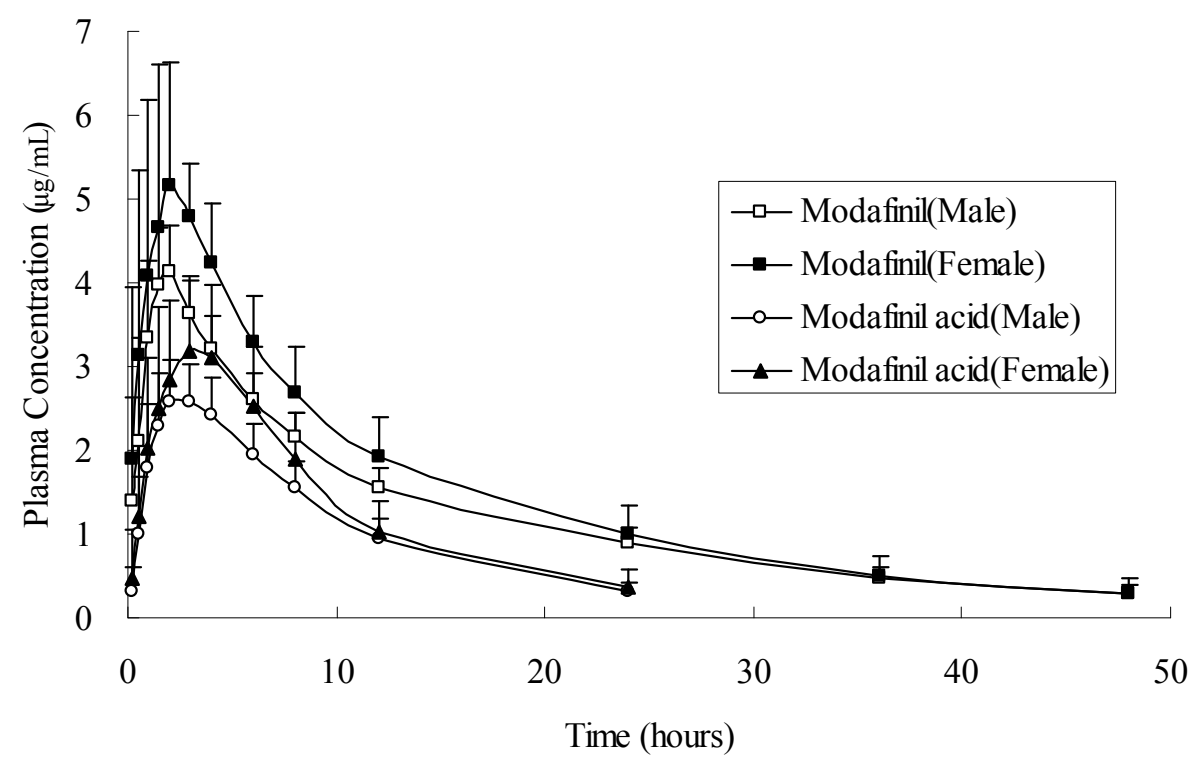

Figure 3. Plasma concentration - time profiles of modafinil and modafinil acid in both sexs. Each point represents mean $\pm \mathrm{SD}$ $($ Male $=24$, Female $=25)$ 


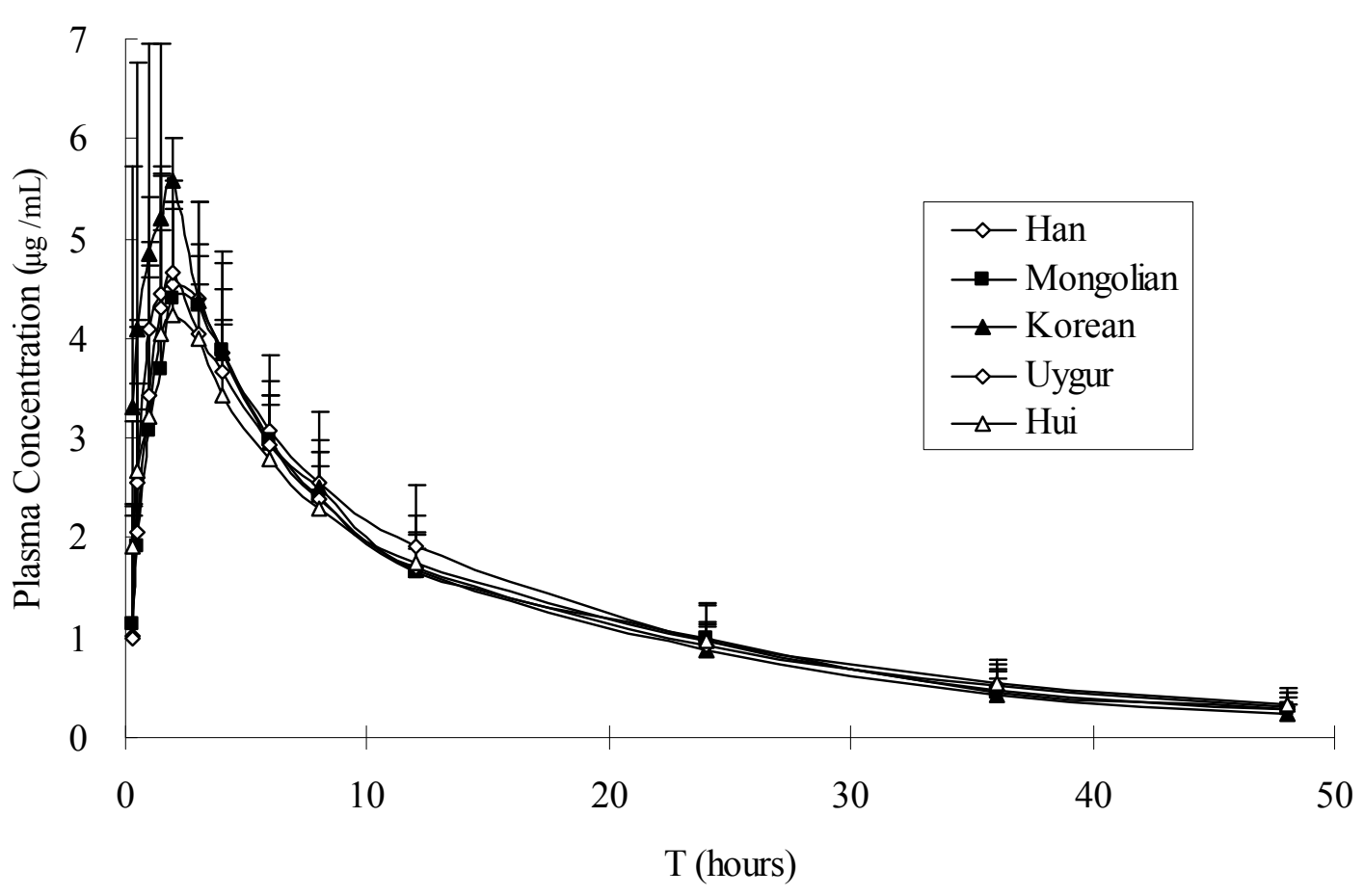

Figure 4. Plasma concentration - time profiles of modafinil in the five ethnicities of China. Each point represents mean $\pm \operatorname{SD}($ Han=10, Mongolian=10, Korean=9, Uygur=10, Hui=10 ).

\begin{tabular}{|c|c|c|c|c|c|c|}
\hline Subject & $\begin{array}{l}T_{\max } \\
\text { (h) }\end{array}$ & $\begin{array}{c}\mathrm{C}_{\max } \\
(\mu \mathrm{g} / \mathrm{mL})\end{array}$ & $\begin{array}{l}t_{1 / 2} \\
\text { (h) }\end{array}$ & $\begin{array}{c}\text { CLF } \\
(\mathrm{mL} / \mathrm{min} / \mathrm{kg})\end{array}$ & $\begin{array}{l}\mathrm{Vd} / \mathrm{F} \\
(\mathrm{L} / \mathrm{kg})\end{array}$ & $\begin{array}{c}\mathrm{AUC}_{0-\infty} \\
(\mu \mathrm{g} \cdot \mathrm{h} / \mathrm{mL})\end{array}$ \\
\hline Han & $1.6 \pm 0.7$ & $5.15 \pm 1.08$ & $11.4 \pm 1.5$ & $0.84 \pm 0.15$ & $0.82 \pm 0.11$ & $71.0 \pm 22.6$ \\
\hline Mongolian & $2.2 \pm 0.8$ & $4.86 \pm 0.67$ & $12.7 \pm 3.2$ & $0.76 \pm 0.11$ & $0.82 \pm 0.19$ & $68.6 \pm 11.6$ \\
\hline Korean & $1.6 \pm 0.5$ & $5.88 \pm 1.78$ & $11.8 \pm 2.0$ & $0.88 \pm 0.19$ & $0.88 \pm 0.13$ & $69.9 \pm 14.9$ \\
\hline Hygur & $1.8 \pm 0.5$ & $4.79 \pm 0.68$ & $15.0 \pm 4.0^{\mathrm{a}}$ & $0.83 \pm 0.20$ & $1.04 \pm 0.20^{\mathrm{a}}$ & $70.9 \pm 15.7$ \\
\hline Hui & $1.9 \pm 0.9$ & $4.74 \pm 1.01$ & $14.0 \pm 2.1^{\mathrm{a}}$ & $0.81 \pm 0.15$ & $0.96 \pm 0.10^{\mathrm{a}}$ & $70.6 \pm 20.0$ \\
\hline
\end{tabular}

Similar to previous findings (16), $C_{\max }, \mathrm{CL} / \mathrm{F}$ and $\mathrm{AUC}_{0-\infty}$ in healthy young females were higher than those found in males, but Wong YN et al reported that the $\mathrm{CL} / \mathrm{F}$ of modafinil in females was approximately $22 \%$ higher $(p<0.05)$ than that in males, while the current study found no significant difference of $\mathrm{CL} / \mathrm{F}$ across sexes. However, the results of table 3 indicate that the $C_{\max }$ and $\mathrm{AUC}_{0-\infty}$ of modafinil and modafinil acid in Chinese were higher than that in Caucasians with the same dose of $200 \mathrm{mg}$ modafinil. And so does the $t_{1 / 2}$ for both modafinil and modafinil acid which were longer. The possible reason for this difference might be the influence of ethnicity between white Caucasian and
Person of Asian descent which should be further investigated.

The results also indicate that there might be some sex differences among the five groups above according to the values of $t_{1 / 2}$ and $V d / F$. The total amount of modafinil acid detected in the plasma was not similar between young males and females $(p<0.05)$, and the concentration of modafinil acid at $48 \mathrm{~h}$ after administration could not be detected. The main pharmacokinetic parameters of modafinil acid were higher in females than in males, regardless of $t_{1 / 2}$, and the possible reasons about this might be the cytochrome $\mathrm{P} 450(\mathrm{CYP}) 3 \mathrm{~A} 4$ is involved in modafinil metabolism, while some 
evidence suggests that young women may have approximately 1.4 times the CYP3A4 activity of men(21), so modafinil and modafinil acid eliminate much faster in females than that of males, with shorter $t_{1 / 2}$ for females than that of males.

In conclusion, the findings from the current study may indicate that the pharmacokinetic differences exist for modafinil across sex and ethnicity. The shortage of this study is whether the number could stand for the whole population of sex and ethnicity in China, which should be further studied.

\begin{tabular}{|c|c|c|c|c|c|c|}
\hline Parameters & $\begin{array}{l}T_{\max } \\
\text { (h) }\end{array}$ & $\begin{array}{c}\mathrm{C}_{\max } \\
(\mu \mathrm{g} / \mathrm{mL})\end{array}$ & $\begin{array}{l}t_{1 / 2} \\
\text { (h) }\end{array}$ & $\begin{array}{c}\text { CL/F } \\
(\mathrm{mL} / \mathrm{min} / \mathrm{kg})\end{array}$ & $\begin{array}{l}\mathrm{Vd} / \mathrm{F} \\
(\mathrm{L} / \mathrm{kg})\end{array}$ & $\begin{array}{c}\mathrm{AUC}_{0 \infty} \\
(\mu \mathrm{g} \cdot \mathrm{h} / \mathrm{mL})\end{array}$ \\
\hline \multicolumn{7}{|l|}{ Modafinil } \\
\hline \multicolumn{7}{|l|}{ Wong et al (16) } \\
\hline Young males & $2.0 \pm 1.0$ & $4.21 \pm 0.44$ & $12.7 \pm 3.2$ & $0.72 \pm 0.10$ & $0.77 \pm 0.11$ & $57.0 \pm 7.6$ \\
\hline Young females & $1.7 \pm 0.9$ & $5.20 \pm 0.83^{\mathrm{a}}$ & $10.5 \pm 1.5$ & $0.88 \pm 0.17^{\mathrm{a}}$ & $0.78 \pm 0.09$ & $61.3 \pm 12.6$ \\
\hline \multicolumn{7}{|l|}{ In this study } \\
\hline Young males & $1.8 \pm 0.7$ & $4.33 \pm 0.49$ & $13.8 \pm 3.0$ & $0.81 \pm 0.14$ & $0.95 \pm 0.17$ & $64.1 \pm 10.8$ \\
\hline Young females & $1.9 \pm 0.8$ & $5.78 \pm 1.13^{\mathrm{a}}$ & $12.2 \pm 2.8$ & $0.84 \pm 0.18$ & $0.87 \pm 0.17$ & $76.1 \pm 19.3^{\mathrm{a}}$ \\
\hline \multicolumn{7}{|l|}{ Modafinil acid } \\
\hline \multicolumn{7}{|l|}{ Wong et al (16) } \\
\hline Young males & $2.8 \pm 1.0$ & $2.06 \pm 0.32$ & $5.7 \pm 0.5$ & NA & NA & $22.8 \pm 3.0$ \\
\hline Young females & $2.9 \pm 0.9$ & $2.65 \pm 0.46^{\mathrm{a}}$ & $4.7 \pm 0.5^{\mathrm{a}}$ & NA & NA & $22.5 \pm 4.9$ \\
\hline \multicolumn{7}{|l|}{ In this study } \\
\hline Young males & $2.5 \pm 0.9$ & $2.73 \pm 0.50$ & $7.3 \pm 2.1$ & NA & NA & $32.4 \pm 6.6$ \\
\hline Young females & $3.0 \pm 1.2$ & $3.47 \pm 0.82^{a}$ & $6.5 \pm 2.2$ & NA & NA & $37.9 \pm 10.2^{\mathrm{a}}$ \\
\hline
\end{tabular}

NA, not applicable.

a. There was a significant difference between young males and females $(\mathrm{p}<0.05)$. The $C_{\max }$ and $\mathrm{AUC}_{0-\infty}$ of modafinil and modafinil acid were significantly larger $(\mathrm{p}<0.05$, respectively) in the female group compared to the male group. The $C_{\max }$ of modafinil was also significantly different across the five ethnicities.

\section{REFERENCES}

1. Bastuji H, Jouvet M. Successful treatment of idiopathic hypersomnia and arcolepsy with modafinil. Prog Neuropsychopharmacol Biol Psychiatry, 1988;12:695-700.

2. Ivanenko A, Tauman R, Gozal D. Modafinil in the treatment of excessive daytime sleepiness in children. Sleep Med, 2003; 4:579-582.

3. Walsh JK, Randazzo AC, Stone KL, Schweitzer PK. Modafinil improves alertness, vigilance, and executive function during simulated night shifts. Sleep, 2004; 27:434-439.

4. Pack AI, Black JE, Schwartz JR, Matheson JK. Modafinil as adjunct therapy for daytime sleepiness in obstructive sleep apnea. Am J Respir Crit Care Med, 2001; 164: 1675-1681.

5. Rammohan KW, Rosenberg JH, Lynn DJ, Blumenfeld AM, Pollak CP, Nagaraja HN. Efficacy and safety of modafinil (Provigil) for the treatment of fatigue in multiple sclerosis: a two centre phase 2 study. J Neurol Neurosurg Psychiatry, 2002; 72: 179-183.

6. Adler CH, Caviness JN, Hentz JG, Lind M, Tiede J. Randomized trial of modafinil for treating subjective daytime sleepiness in patients with Parkinson's disease. Mov Disord, 2003; 18:287-293.

7. MacDonald JR, Hill JD, Tarnopolsky MA. Modafinil reduces excessive somnolence and enhances mood in patients with myotonic dystrophy. Neurology, 2002;59: 1876-1880.

8. DeBattista C, Doghramji K, Menza MA, Rosenthal MH, Fieve RR, Modafinil in Depression Study Group. Adjunct modafinil for the short-term treatment of fatigue and sleepiness in patients with major depressive disorder: a preliminary double-blind, placebo-controlled study. J Clin Psychiatry, 2003; 4: 1057-1064.

9. Rosenthal MH, Bryant SL. Benefits of adjunct modafinil in an open-label, pilot study in patients with schizophrenia. Clin Neuropharmacol, 2004; 27:38-43.

10. Swanson JM, Greenhill LL, Lopez FA, Sedillo A, Earl CQ, Jiang JG, Biederman J. Modafinil film-coated tablets in children and adolescents with attention-deficit/hyperactivity disorder: results of a randomized, double-blind, placebo-controlled, fixed-dose study followed by abrupt discontinuation. J Clin Psychiatry, 2006; 67: 137-147.

11. Vocci FJ, Elkashef A. Pharmacotherapy and other 
treatments for cocaine abuse and dependence. Curr Opin Psychiatry, 2005; 18:265-270.

12. Wisor JP, Eriksson KS. Dopaminergic-adrenergic interactions in the wake promoting mechanism of modafinil. Neuroscience, 2005; 132:1027-1034.

13. Jasinski DR, Kovacević-Ristanović R. Evaluation of the abuse liability of modafinil and other drugs for excessive daytime sleepiness associated with narcolepsy. Clin Neuropharmacol, 2000; 23:149-156.

14. Makris AP, Rush CR, Frederich RC, Kelly TH. Wake-promoting agents with different mechanisms of action: comparison of effects of modafinil and amphetamine on food intake and cardiovascular activity. Appetite, 2004; 42:185-195.

15. Hirshkowitz M, Black J. Effect of adjunctive modafinil on wakefulness and quality of life in patients with excessive sleepiness-associated obstructive sleep apnoea/hypopnoea syndrome: a 12-month, open-label extension study. CNS Drugs, 2007; 21:407-416.

16. Wong YN, King SP, Simcoe D, Gorman S, Laughton W, McCormick GC, Grebow P. Open-label, single-dose pharmacokinetics study of modafinil tablets: Influence of age and gender in normal subjects. J Clin Pharmacol, 1999; 39:281-288.

17. Moachon G, Kanmacher I, Clenet M, Matinier D. Pharmacokinetic profile of modafinil. Drugs Today, 1996; 32:327-337.

18. Johnson JA. Influence of race or ethnicity on pharmacokinetics of drugs. J Pharm Sci, 1997; 86:1328-1333.

19. Wood AJ, Zhou HH. Ethnic differences in drug disposition and responsiveness. Clin Pharmacokinet 1991;20: 350-373.

20. Magee $\mathrm{MH}$, Blum RA, Lates CD, Jusko WJ. Prednisolone pharmacokinetics and pharmacodynamics in relation to sex and race. J Clin Pharmacol, 2001; 41, 1180-1194.

21. Harris RZ, Benet LZ, Schwartz JB. Gender effects in pharmacokinetics and pharmacodynamics. Drugs, 1995; 50:222-239.

22. Zhao LS, Xia DY, Guo T. Determination of modafinil and modafinil acid in human plasma by HPLC with UV detection. Chin J Pharm Anal, 2007; 27: 1863-1866.

23. Sanford B, Charles Bon. Pharmaceutical Statistics: Practical and Clinical Applications [M]. 4rded. New York, NY: Marcel Dekker. 2004,173-228.

24. Wong YN, Simcoe D, Hartman LN, Laughton WB, King SP, McCormick GC, Grebow PE. A double-blind, placebo-controlled, ascending-dose evaluation of the pharmacokinetics and tolerability of modafinil tablets in healthy male volunteers. J Clin Pharmacol, 1999; 39: 30-40.

25. Wong YN, King SP, Laughton WB, McCormick GC, Grebow PE. Single-dose pharmacokinetics of modafinil and methylphenidate given alone or in combination in healthy male volunteers. J Clin Pharmacol, 1998; 38:276 -282.

26. Wong YN, Wang L, Hartman L, Simcoe D, Chen Y, Laughton W, Eldon R, Markland C, Grebow P. Comparison of the single-dose pharmacokinetics and tolerability of modafinil and dextroamphetamine administered alone or in combination in healthy male volunteers. J Clin Pharmacol, 1998; 38:971-978. 